ON AN

ATTEMPTED SUICIDE BY A WOUND OF THE THORAX, AFTER TAKING A LARGE QUANTITY OF LAUDANUM.

PLEURITIS, EMPYEMIA, AND RECOVERY.

By C. L. ALLWORK, Ese., M.R.C.S., \&c., Maidstone.

H. C., aged 27, a solicitor's clerk, of spare frame and excitable temperament, had been observed to be in a desponding mood for some days, owing, as it was subsequently ascertained, to a circumstance which had transpired in a burial society for which he was secretary.

On the evening of the 5 th of October, 1848, he called at a public-house and requested to engage a bed for the night. The landlord noticed him pale and haggard-this was attributed to fatigue. After partaking of some brandy he retired for the night, and nothing more was seen of him till the next morning, when the proprietor of the house, on going into his room, found him sitting up in bed with a large pocket-knife in his hand, and the bedclothes saturated with blood. I was then sent for, and on examining to find the source of the hremorrhage, found it to proceed from a penetrating wound in the chest, about two inches below and in a line with the left nipple, which appeared to have taken a direction downwards through the intercostal muscle the edges of which were gaping. Hæmorrhage having ceased, I drew the edges of the wound together, retaining them by strips of Macord's plaster, and on my leaving I requested that he might be closely watched. I had scarcely reached my residence (not many yards off) when I was again summoned, in consequence of a discovery which had been made by his brother, who, on searching his pockets, found four vials, two of one ounce, and two of one ounce and a half, and labelled "laudanum." On questioning him, he acknowledged having taken on the previous night five ounces of the poison; he further stated that he had not vomited, that he had remained in a restless and excited state the whole night, and that this having failed in producing the effect he intended, he had resolved on terminating his existence by the expedient before detailed. There was little about his appearance, save a contracted state of the pupil, to indicate his having swallowed the enormous quantity of poison, nor had he, so far as I could learn, heen in the habit of taking the drug; but believing, if he had, that it was probable the poison was, from some cause or another, still in the stomach, I determined on employ. ing the stomach-pump, which brought up a large quantity of brownish fluid, having the smell and appearance of laudanum. In a short time he relapsed into a state of stupor, and continued so throughout the day and night, the attendants having considerable difficulty in arousing him; coffee and saline aperients were administered, which acted freely on the bowels. On the evening of the 7 th, symptoms of acute pleurisy set in, for which he was bled three times before the severe symptoms yielded. Leeches were also applied in the neighbourhood of the wound, and calomel, opium, and antimony administered. It will not be necessary to detail the symptoms and treatment from day to day through an illness of more than two months, but simply to state that towards the close, undeniable symptoms and signs of empyema manifested themselves, the left side measuring an inch and $a$ half from the spine to the sternum more than the right side, and the patient was worn to a shadow by hectic at the close of his illness. During a severe fit of coughing he expectorated a large quantity of unhealthy pus, and which he continued to do for some days. From that moment he began to recover, and he is now in his usual state of health.

My thanks are especially due to Dr. Taylor of this town for his valuable co-operation in the treatment of this singular case.

Maidstone, July, 1850.

\section{Rebiéns and Notices.}

Report on the Training and Teaching of Idiots, presented to the Governor of the Commonwealth of Massachusetts. By S. G. Rowe, M.D. Boston, U.S. 1850 . pp. 72.

IDIOCr, the greatest calamity incident to frail human nature, has recently attracted considerable attention, with a view to its alleviation, not only in several countries of Europe, but likewise in the United States of America, as proved by the official Report whose title heads this article. In France, for instance, under the benevolent exertions of $M$. Noisin at Bicêtre, the great experiment of educating idiots has now been in operation for several years; and the sanguine hopes entertained that some of these unfortunate beings would be converted into moral and useful members of society, have been realized; and as we ourselves visited this admirable establishment not long ago, and carefully examined into its working, such an institution, in our opinion, well deserves the encomiums it has so often received. In Switzerland, again, through the judicious labours of Dr. Guggenbuihl, at Abendberg, much has been accomplished towards improving the moral and physical condition of idiots and cretins - unfortunately numerous in the Alpine valleys of that romantic country; whilst in England the subject has not been overlooked by modern philanthropists, seeing an asylum for idiots has been lately instituted, mainly through the influence of the Rev. Dr. Reed, aided by a few medical practitioners, and is now in active operation near Highgate; to which we may, perhaps, at a future period, allude more particularly, should the official reports of its proceedings reach us. In the meantime, however, our present remarks will be confined to the public document now before us, the more so as it comes from beyond the Atlantic, to show that the new world follows the old, in the onward movement of civilization.

According to the Report, it seems to have been ascertained, that in nearly one hundred towns, in different parts of the state of Massachusetts, not less than 575 human beings were in a hopeless condition of idiocy during the year 1848; of whom 420 were considered properly idiotic, their feebleness of intellect being connate; whilst the remaining 155 had become so after birth. Of these 420,187 were under twentyfive years of age; 218 were insatiable gluttons, and 102 were known to be addicted to masturbation in a frightful degree. Respecting the causes of idiocy, the Report lays much stress upon two-the first being the low condition of the physical organization of both parents; the second, the intermarriage of relatives. Upon both these points many interesting details are given; but into such important inquiries our limited space will not allow us to enter further than to say, that unquestionably in this malady, as in many cases of mania and some other diseases, hereditary taint and intemperance were frequently ascertained to have exerted considerable influence in its production. Thus, in 354 instances out of the 420 cases of congenital idiocy, it was found that one or both of the immediate progenitors of the afflicted sufferer had been very unhealthy, or scrofulous; some were hereditarily predisposed to affections of the brain; others had been intemperate, or had been guilty of unusual excesses, which impair the constitution; whilst others had intermarried with blood relatives.

The reporter next discusses the objects to be aimed at in the training of idiots; next, the importance of a proper classification of such patients, with the use of language as a basis of classification, and the indirect benefits of a school; subsequently he discusses physical or bodily training for developing mental power; and lastly, the best method of educating the idiotic. Upon each of these topics Dr. Rowe enters at some length; and although it is impossible to follow the learned reporter through all his disquisitions, we must candidly say, his lucubrations are sometimes rather obscure, if not occasionally so verbose, that condensation of the reasoning employed, and a more succinct array of the facts enunciated, would prove more useful and instructive than the diffuse method adopted throughout the narrative, which nevertheless deserves attentive perusal.

Respecting the results, which, after all, is the most important feature in the matter under discussion,-for by the fruits produced must its value be tested, - it seems to have been gratifying and encouraging. Of the whole number received into the institution at Boston, there was not one who seemed in a situation where very great improvement in the individual's condition was probable, or hardly possible, seeing they were previously growing worse in habits, and more confirmed in 